Research Article

\title{
Study of prescribing pattern of antimicrobial agents in indoor patients of a tertiary care hospital
}

\author{
Vinod S. Deshmukh*, Vyankatesh V. Khadke, Arun W. Patil, Pravin S. Lohar
}

Department of Pharmacology, SRTR Government Medical College, Ambajogai, DistrictBeed, Maharashtra, India

Received: 16 March 2013 Accepted: 8 April 2013

\section{*Correspondence to:}

Dr. Vinod S. Deshmukh,

Email:

vinod_deshmukh88@yahoo.com

(C) 2013 Deshmukh VS et al. This is an open-access article distributed under the terms of the Creative Commons Attribution License, which permits unrestricted use, distribution, and reproduction in any medium, provided the original work is properly cited.

\begin{abstract}
Background: To evaluate prescribing pattern of antimicrobial agents in indoor patients of medicine and surgery department of SBH Government Medical College, Dhule.

Methods: This was a retrospective cross sectional study carried over a period of 3 months. The patients who were admitted and received antimicrobial therapy in department of Medicine and Surgery were randomly selected and included in the study. The case record sheet and drug chart were obtained from Medical Record Section of the Hospital. The data was collected using case record form specially prepared for the study. The cases were categorised according to slightly Modified Kunin's Criteria.

Results: Total numbers of patients receiving antimicrobial therapy were 130 in medicine department and 93 in surgery department. Most commonly prescribed antimicrobial agent was cefotaxime $(21.7 \%)$ in medicine and metronidazole in surgery $(30.6 \%)$ department. The average number of antimicrobials per patient was found to be 1.7 and 3.02 in medicine and surgery department respectively. The switch on therapy from parenteral to oral route was employed in $16.15 \%$ patients in medicine department and $11.82 \%$ patients in surgery department. As per Kunin's modified criteria, $66.2 \%$ and $58.06 \%$ patients received antimicrobial therapy appropriately in Medicine and surgery department respectively.

Conclusion: This study highlights the problem of over-prescription of antibiotics and a trend towards polypharmacy. The interventions to rectify the problem of inappropriate use of antimicrobial agents are needed to make therapy more rational and cost effective.
\end{abstract}

Keywords: Antimicrobial agents, Prescription pattern, Modified Kunin's criteria, Indoor patients

\section{INTRODUCTION}

Quality of life can be improved by enhancing the standards of medical treatment at all levels of health care delivery system. Drugs are one of the most important part of medical treatment. Because of important contribution of drugs to the life, use of drugs should be rational. WHO has defined rational use of drugs when "patients receive medications appropriate to their clinical needs, in doses that meet their own individual requirements, for an adequate period of time, and at the lowest cost to them and their community."1

Rational drug prescribing has been shown to reduce the cost of treatment, adverse drug reactions. ${ }^{2}$ Despite advances in control of drug regulation and availability of drugs, the irrational drug prescribing is still worldwide concern.

Many a times desire of the physician to do something for the patient and to prescribe a "Pill for every ill" leads to over prescribing. Various studies indicate that out of total drugs prescribed, 28 to $42 \%$ of the drugs are antimicrobial agents. Around $50 \%$ of these prescriptions of antimicrobial agents are not needed, are inappropriate or are in wrong doses. The fear of physician whether he is missing any occult infection also makes him to use antibiotic "umbrella" for protecting him and his patient. ${ }^{3}$ The extremely high efficacy of antimicrobial agents has proved to be a boon and curse. The double edged sword has now many more edges; the sharpest is the development of resistance to antimicrobial agents. ${ }^{4}$ 
Prescribing drugs is a skill that needs to be assessed and redefined continuously. Prescription pattern reflects health professional attitude towards the disease and role of drugs in its treatment, and their therapeutic knowledge. Auditing of prescriptions also forms a part of drug utilization study. ${ }^{5}$ With large number of patients being admitted in our tertiary care hospital and health services being catered from junior resident to unit in-charge, it is expected that there may be a lot of variations in the prescribing of drugs and prescription study may be helpful to know if there is a problem of irrational use of drugs and to what extent.

With this background, the present study was planned to evaluate prescribing pattern of antimicrobial agents in indoor patients of medicine and surgery department of SBH Government Medical College, Dhule.

\section{METHODS}

The present study was carried out in indoor patients of Medicine and Surgery Department of SBH Government Medical College, Dhule. The permission of Institutional Ethics committee was obtained prior to the study. This was a retrospective cross sectional study carried over a period of 3 months. The patients who were admitted and received antimicrobial therapy in department of Medicine and Surgery were randomly selected and included in the study. The case record sheet and drug chart were obtained from Medical Record Section of the Hospital.

The data was collected using case record form specially prepared for the study. The first part of Case Record Form contains patient information such as name, age, sex, registration number, date of admission, date of discharge, duration of stay in hospital etc. The second part of the case record form contains details of antimicrobial prescribed such as name of anti-microbial agent, category of anti-microbial agent, dosage form, route of administration, quantity prescribed, average number of anti-microbial prescribed per prescription, department wise distribution of anti-microbial use, use of anti-microbial for therapeutic or prophylactic purpose, etc. The additional data regarding switch on therapy from parenteral to oral route, number of anti-microbial used in surgical prophylaxis were also recorded.

The cases were categorised according to slightly Modified Kunin's Criteria.

Category I: Agree with the use of anti-microbial therapy/prophylaxis, the programme is appropriate.

Category II: Agree with use of anti-microbial therapy/prophylaxis, but a potentially fatal bacterial infection cannot be ruled out or prophylaxis is probably appropriate although advantage derived remain controversial.

Category IIa: Agree with the use of one anti-microbial agent but the use of other( $s)$ is unjustified.
Category III: Agree with the use of anti-microbial therapy/prophylaxis, but a different antimicrobial is preferred (usually less expensive or less toxic).

Category IV: Agree with the use of anti-microbial therapy/prophylaxis, but a modified dose and or /proper duration is recommended.

Category V: Disagree with the use of anti-microbial therapy/prophylaxis, administration is unjustified.

Categories I, II and IIa essentially indicate appropriate therapy whereas categories III, IV, and V indicate that there was some major deficiency in the choice or use of anti-microbial agent by the physicians managing the problem.

Category of antimicrobial use in Modified Kunin's Criteria was decided according to standard treatment guidelines and antibiotic policy of institute.

The data was entered in Microsoft Office Excel 2007. The results were calculated as average or percentage, as applicable.

\section{RESULTS}

Table 1: Commonly prescribed antimicrobial agents.

\begin{tabular}{|lll|}
$\begin{array}{l}\text { Name of } \\
\text { Antimicrobial } \\
\text { Agents }\end{array}$ & $\begin{array}{l}\text { Medicine } \\
(\%)\end{array}$ & \multicolumn{1}{c|}{$\begin{array}{c}\text { Surgery } \\
(\%)\end{array}$} \\
\hline Cefotaxime & $48(21.7)$ & $72(25.6)$ \\
\hline Ciprofloxacin & $43(19.4)$ & $36(12.8)$ \\
\hline Metronidazole & $43(19.4)$ & $86(30.6)$ \\
\hline Ceftriaxone & $31(14.02)$ & $04(1.4)$ \\
\hline Ampicillin & $29(13.1)$ & $04(1.4)$ \\
\hline Gentamycin & $04(1.8)$ & $54(19.2)$ \\
\hline Amikacin & $10(4.5)$ & $04(1.4)$ \\
\hline Others & $13(5.8)$ & $21(7.4)$ \\
\hline $\begin{array}{l}\text { Total } \\
\text { Antimicrobial } \\
\text { Agents }\end{array}$ & 221 & 281 \\
\hline $\begin{array}{l}\text { Total number of } \\
\text { patients }\end{array}$ & 130 & 93 \\
\hline Cefotaxime & $48(21.7)$ & $72(25.6)$ \\
\hline Ciprofloxacin & $43(19.4)$ & $36(12.8)$ \\
\hline $\begin{array}{l}\text { Average number of } \\
\text { Antimicrobial } \\
\text { Agents }\end{array}$ & 1.7 & 3.02 \\
\hline
\end{tabular}

Total numbers of patients receiving antimicrobial therapy in medicine department were found to be 130 . Of the total 130 patients, 40 patients were receiving antimicrobial agents prophylactically where as 90 patients were receiving it as treatment. In surgery department total 93 patients were receiving antimicrobial therapy. Of these 70 patients were receiving it as prophylactic measure and remaining 23 patients were receiving antimicrobials as therapeutic measure. 
As shown in Table1, most commonly prescribed antimicrobial agent was cefotaxime $(21.7 \%)$ in medicine and metronidazole in surgery $(30.6 \%)$ department.
Total number of antimicrobials prescribed was 221 in medicine and 281 in surgery department with average number of antimicrobials per patient was found to be 1.7 and 3.02 respectively.

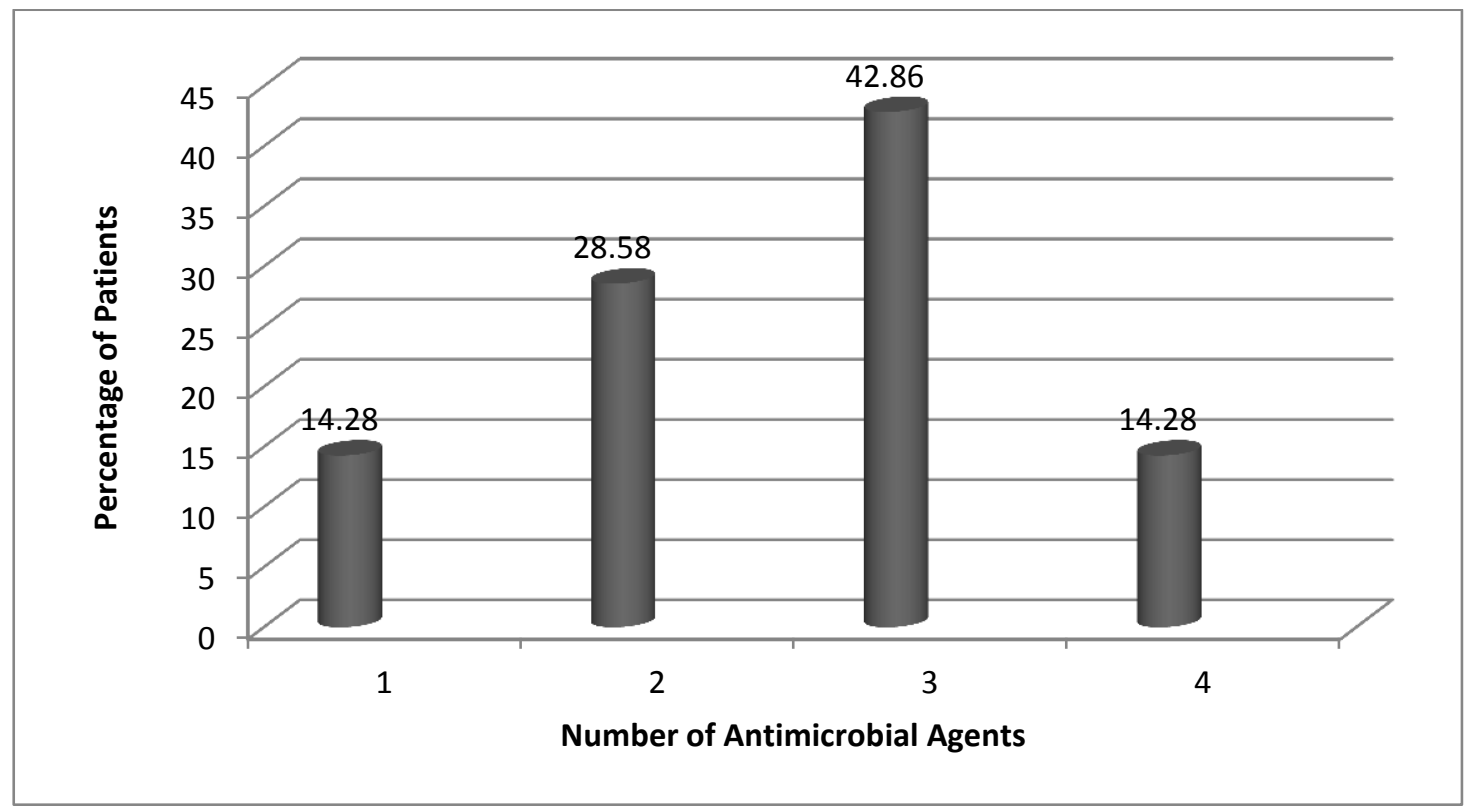

Figure 1: No. of antimicrobial agents used in surgical prophylaxis.

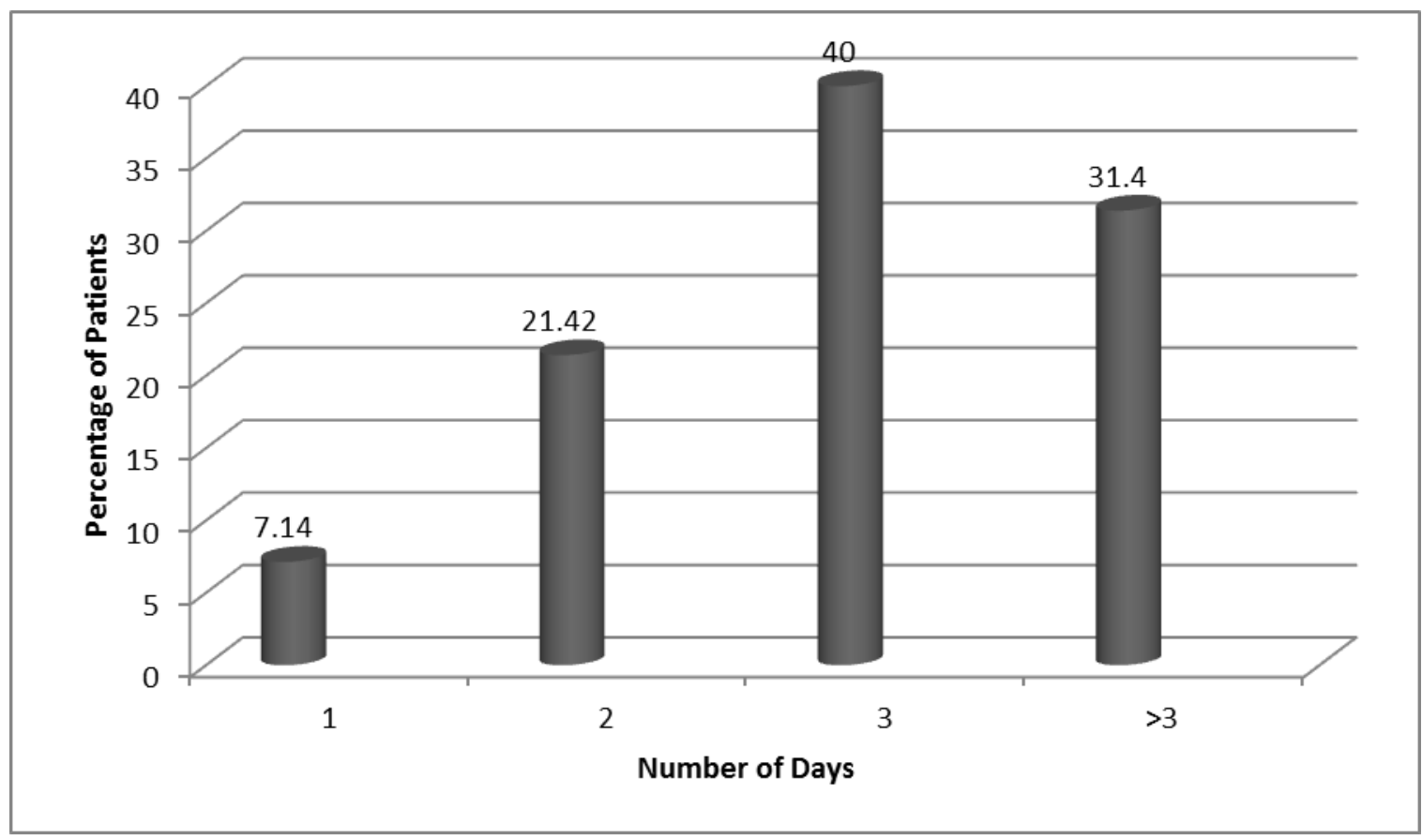

Figure 2: Duration of surgical prophylaxis.

As shown in Figure 1, total 70 patients received antimicrobial agents for surgical prophylaxis with range of 1-4 antimicrobial per patient. The maximum $42.86 \%$ patients received 3 antimicrobial agents for surgical prophylaxis.
The duration for which the antimicrobial agents were prescribed for surgical prophylaxis is as shown in the Figure 2. The maximum number of patients i.e. $40 \%$ received antimicrobials prophylaxis for 3 days. In $31.4 \%$ of the patients the duration was more than 3 days. 
The switch on therapy from parenteral to oral route was employed in $16.15 \%$ patients in medicine department and
$11.82 \%$ patients in surgery department (Figure 3).

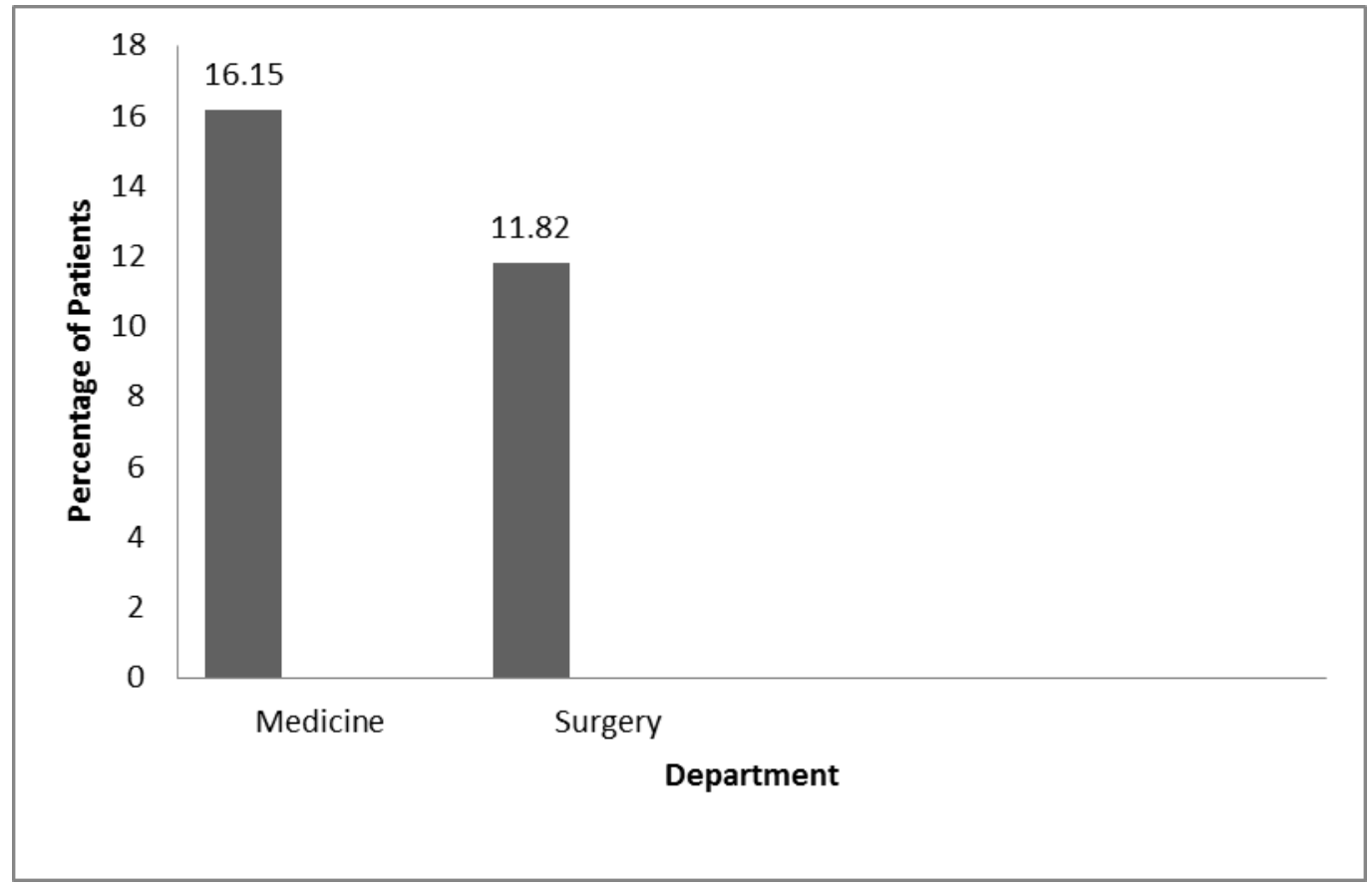

Figure 3: Switch On Therapy from parenteral to oral route of administration.

Table 2: Type of use of anti-microbial agents and categorisation of anti-microbial use according to modified Kunin's criteria.

\begin{tabular}{|c|c|c|c|c|c|c|c|c|c|c|}
\hline \multirow[t]{2}{*}{ Speciality } & \multirow[t]{2}{*}{ Type of Use } & \multicolumn{3}{|c|}{ Appropriate } & \multirow{2}{*}{$\begin{array}{l}\text { Sub- } \\
\text { Total }\end{array}$} & \multicolumn{3}{|c|}{ Inappropriate } & \multirow{2}{*}{$\begin{array}{l}\text { Sub- } \\
\text { total }\end{array}$} & \multirow{2}{*}{$\begin{array}{l}\text { Total } \\
\text { Number of } \\
\text { Patients }\end{array}$} \\
\hline & & I & II & IIa & & III & IV & $\mathbf{V}$ & & \\
\hline \multirow[t]{2}{*}{ Medicine } & Prophylactic & 07 & 12 & 03 & 22 & 01 & 07 & 10 & 18 & 40 \\
\hline & Therapeutic & 24 & 20 & 20 & 64 & 03 & 10 & 13 & 26 & 90 \\
\hline $\begin{array}{l}\text { Total number of } \\
\text { patients }(\%)\end{array}$ & & & & & $86(66.2$ & & & & $44(33.8)$ & 130 \\
\hline \multirow[t]{2}{*}{ Surgery } & Prophylactic & 14 & 03 & 16 & 33 & 08 & 22 & 07 & 37 & 70 \\
\hline & Therapeutic & 14 & 02 & 05 & 21 & 01 & 01 & 00 & 02 & 23 \\
\hline $\begin{array}{l}\text { Total number of } \\
\text { patients }(\%)\end{array}$ & & & & & $54(58$. & & & & $39(41.93)$ & 93 \\
\hline
\end{tabular}

As per Kunin's modified criteria, 66.2\% and 58.06\% patients received antimicrobial therapy appropriately in Medicine and surgery department respectively (Table 2).

\section{DISCUSSION}

This study was planned to audit the prescription for generating the baseline data regarding antibiotic utilization in our hospital and to compare it with other similar studies for rational prescribing.
Average number of drugs per prescription is an important indicator of prescription audit. It is preferable to keep the mean number of drugs per prescription as minimum as possible. This will help to avoid the drug-drug interactions, development of bacterial resistance and increase hospital cost. ${ }^{7}$ In our study the average number of antimicrobials prescribed in surgery department was 3.02 per prescription. This is higher than those reported by Sharma D et al which was only $1 .^{8}$ 
Surgical prophylaxis should be strictly peri-operative, beginning not more than few hours before the operation. The aim is to maintain the adequate tissue levels of antibiotic for the duration of operation and few hours afterwards. It should not be given for total period exceeding 24 hours. ${ }^{9}$ In the present study the maximum number $(40 \%)$ of patients received antimicrobial agents for prophylaxis for 3 days. This may leads to unnecessary increase in cost of therapy which puts unnecessary burden on limited resources available.

Intravenous to oral switch therapy has become the mainstay of antibiotic therapy for the majority of patients. Intravenous to oral switch therapy is inappropriate for critically ill patients who require intravenous antibiotic therapy and should not be considered in patients who have the inability to absorb drugs. These exceptions constitute a very small percentage of hospitalized patients for which intravenous to oral switch therapy is not ideal. $^{10}$

In present study switch on therapy was used only in small number of patients, i.e. $16.15 \%$ in medicine and $11.82 \%$ in surgery.

Modified Kunin's Criteria was used to assess whether antibiotics are prescribed appropriately or not. In present study, according to Modified Kunin's Criteria only $66.2 \%$ of the patients in medicine department and $58.06 \%$ of the patients in surgery department had received antibiotics appropriately. In medicine department most of the antimicrobial agents were used indiscriminately in patients of pyrexia of short duration without localizing signs (viral fever). There is no rationale for antimicrobial use in pyrexia of short duration without localizing signs except in toxic patients. ${ }^{11}$

Such type of studies provides necessary feedback to prescribing physicians and may prove useful to formulate antibiotic policy to policy makers.

\section{CONCLUSION}

The present study provides baseline data of prescribing pattern of antimicrobial agents in indoor patients of medicine and surgery department. This study highlights the problem of over-prescription of antibiotics and a trend towards polypharmacy. The interventions to rectify the problem of inappropriate use of antimicrobial agents are needed to make therapy more rational and cost effective.

Funding: No funding sources

Conflict of interest: None declared

Ethical approval: Approval was taken from the Institutional Ethics Committee

\section{REFERENCES}

1. Rational use of medicine. World Health Organisation. Available at http://www.who.int/medicines/areas/ rational use/en/. Accessed 12 December 2012.

2. Pramil T, Rajiv A, Gaurav G. Pattern of prescribing at a paediatric outpatient setting in northern India. IJOPP 2012;5:40-4.

3. Hamilton-Miller JM. Use and abuse of antibiotics. $\mathrm{Br}$ J Clin Pharmacol 1984;18:469-74.

4. Kunin CM, Tupasi T, Craig WA. Use of antibiotics a brief exposition of the problem and some tentative solution. Ann Int Med 1973;79:555-60.

5. WHO regional publications. Studies in drug utilization. European Series No. 8. Copenhagen: WHO Regional Publications, 1979.

6. Vishwanathan N, Gandhi IS, Shashidran $\mathrm{CH}$, Adithan C. Drug utilization study of anti-microbial agents. Indian J Med Res 1981;74:772-8.

7. Atanasova I, Terziivanov D. Investigation on antibiotics in a hospital for a one-year period. Int $\mathbf{J}$ Clin Pharmacol Ther 1995;33:32-3.

8. Sharma D, Reeta K, Badyal DK, Garg SK, Bhargava VK. Antimicrobial prescribing pattern in an Indian tertiary hospital. Indian J Physiol Pharmacol 1998;42:533-7.

9. World Health Organisation. Control of antibioticresistant bacteria: Memorandum from a WHO Meeting. Bulletin of the World Health Organization 1983;61(3):423-33.

10. Cunha BA. Intravenous to oral antibiotic switch therapy. Drugs Today (Barc) 2001;37:311-9.

11. Chambers HF, Sande MA. Antimicrobial Agents. In: Goodman and Gillman's The Pharmacological Basis of Therapeutics. Hardman JG, Limbird LE, Molinoff PB, Ruddon RW, Gilman AG, eds. The McGrawHill Companies, Inc., 1996, pp.1054-1055.

doi:10.5455/2319-2003.ijbcp20130609

Cite this article as: Deshmukh VS, Khadke VV, Patil AW, Lohar PS. Study of prescribing pattern of antimicrobial agents in indoor patients of a tertiary care hospital. Int J Basic Clin Pharmacol 2013;2:281-5. 